\title{
As cartas educativas municipais e o reordenamento da rede escolar no Centro de Portugal: das condições demográficas às decisões políticas
}

\author{
A. M. Rochette Cordeiro * \\ Helena Arcanjo Martins ** \\ António Gomes Ferreira***
}

\section{Resumo}

Desde 2005 que se assiste à assunção da Carta Educativa enquanto instrumento legitimador do planeamento estratégico e do reordenamento prospetivo das redes educativas municipais, cujos efeitos mais visíveis são traduzidos pelo encerramento de largas centenas de escolas do ensino primário $\left(1^{\circ}\right.$ Ciclo do ensino básico) e pela construção de centenas de Centros Escolares. O presente artigo, com base numa investigação em curso, em catorze municípios da região central, está focado na identificação e análise das principais tendências de reordenamento da rede educativa do $1^{\circ} \mathrm{Ciclo}$ preconizadas nas respetivas Cartas Educativas e cuja interpretação tem em conta a forma como todo o processo foi encarado, em termos de planeamento. A passagem de um planeamento de caraterísticas centralizadoras a um planeamento estratégico ofereceu ao reordenamento da rede escolar novas lógicas que se traduziram por diferentes respostas por parte dos municípios portugueses.

Palavras-chave: Carta Educativa. Planeamento estratégico. Municípios e rede escolar

\section{Introdução}

Consagrada legalmente em 2003, a Carta Educativa perspetivava-se como um instrumento municipal de planeamento e ordenamento prospetivo da rede

* Universidade de Coimbra -GRUPOEDE/ CEIS 20 - rochettecordeiro@fl.uc.pt

** Universidade de Aveiro - GRUPOEDE/ CEIS 20 - helenaarcanjo.martins@ua.pt

*** Universidade de Coimbra - GRUPOEDE/ CEIS 20 - antonio@fpce.uc.pt 
escolar (aliás, com integração obrigatória nos planos diretores municipais de $2^{\mathrm{a}}$ geração), assumindo o planeamento para as modalidades de ensino e educação não superior: o ensino regular, a educação especial, o ensino profissional, o ensino recorrente e a educação extraescolar, modalidades de educação definidas pela Lei de Bases do Sistema Educativo (LBSE).

Este documento de planeamento da rede escolar - inicialmente designado de "carta escolar" (com a implementação da LBSE) e, anos mais tarde, definido como "carta educativa" (Decreto-Lei 7/2003, de 15 de Janeiro) - traduziu o culminar da tentativa de desencadeamento de um processo de mudança conceptual e metodológica do planeamento da rede educativa do ensino básico, assim como dos avanços efetuados no domínio da participação e valorização dos municípios em matérias da educação. Até então, foi o planeamento tradicional ou compreensivo (limitado à formulação e execução do plano), de carácter centralizado, burocrático e assente na matematização dos fenómenos sociais, em soluções uniformes, neutras, racionais e replicáveis - "a previsão perfeita" - que sustentou o plano de construções escolares executado, em Portugal, desde a década de 30 do século passado.

A rede escolar edificada até finais dos anos 80 , em Portugal, especialmente a do $1^{\circ}$ Ciclo, reflete a vigência do planeamento tradicional na educação e o peso do poder centralista do Estado-nação. Em resultado disso, a rede escolar era caracterizada pela uniformidade e rigidez de soluções, em face das dinâmicas demográficas e pedagógicas em presença, ignorando praticamente as condições locais que, entretanto, se foram alterando. Estas características contribuíram fortemente para que a densa rede de escolas primárias se viesse a mostrar desajustada da realidade, muito por força das transformações demográficas e das acessibilidades observadas nas últimas décadas (CORDEIRO, 2011). Esses fatores contribuiriam inevitavelmente para adensar os problemas de desajustamento, manutenção e governabilidade da rede escolar, situação que se manteria quase inalterada até ao início do século XXI (MATTHEWS et al., 2009; RODRIGUES, 2010).

A LBSE marca indubitavelmente um novo ciclo de mudanças conceptuais, políticas e administrativas que viriam a contribuir para que se operacionalizassem mudanças do paradigma do planeamento educativo, da participação dos municípios e dos modos de reorganização da própria 
rede escolar. Porém, essas mudanças só viriam a ter efetiva tradução com a implementação da Carta Educativa (Decreto-Lei 7/ 2003), na medida em que, ao ser enunciado como instrumento de planeamento prospetivo e territorializado, criava condições para que o município se pudesse afirmar enquanto autor e participante na reorganização da rede escolar municipal. Tais capacidades habilitaram os municípios a "encontrar soluções educativas locais no contexto político nacional" (MATTHEWS et al., 2009, p. 38), embora deva ser afirmado que foram exercidas num quadro de forte regulação estatal.

É à luz deste quadro conceptual que o artigo se perspetivou: num primeiro momento, é dada atenção à compaginação das mudanças conceptuais ocorridas ao nível do planeamento e das suas influências no reordenamento da rede com a evolução da participação do município nesse mesmo planeamento e, num segundo momento, através da análise das soluções plasmadas em diferentes Cartas Educativas, são identificadas e interpretadas as principais tendências de reordenamento da rede, evidenciadas através de alguns casos que correspondem a municípios que se situam em partes bem diferentes do Centro de Portugal (Figura 1). Houve, pois, especial preocupação em contemplar territórios com amplos níveis aplanados, setores onde a rede hidrográfica se apresenta como parte condicionante à mobilidade, ou mesmo territórios onde os sectores de baixa e média montanha condicionam fortemente as acessibilidades, assim como da própria demografia, com a escolha de territórios de alta e baixa densidade em cinco NUT's III ${ }^{1}$ propiciando, deste modo, uma visão muito abrangente e diversificada sobre as soluções de reordenamento da rede escolar territorial. Embora partindo de uma análise de catorze municípios situados na região centro de Portugal, este artigo tem em vista a explicitação das decisões que caracterizaram a elaboração e a aprovação das Cartas Educativas de quatro deles. Com estes casos, é possível evidenciar os diferentes problemas que se colocavam em diferentes municípios, bem como elucidar os aspetos que mais influenciaram as decisões que foram contempladas nas Cartas Educativas aprovadas na segunda parte da primeira década do século XXI.

1 A designação de Nomenclaturas de Unidades Territoriais - NUT III - corresponde (para fins Estatísticos) a uma unidade de território - sub-região - que engloba vários Municípios de características territoriais, demográficas e culturais, idênticas. 
Figura 1 - Enquadramento dos Municípios da amostra no contexto da Região Centro de Portugal

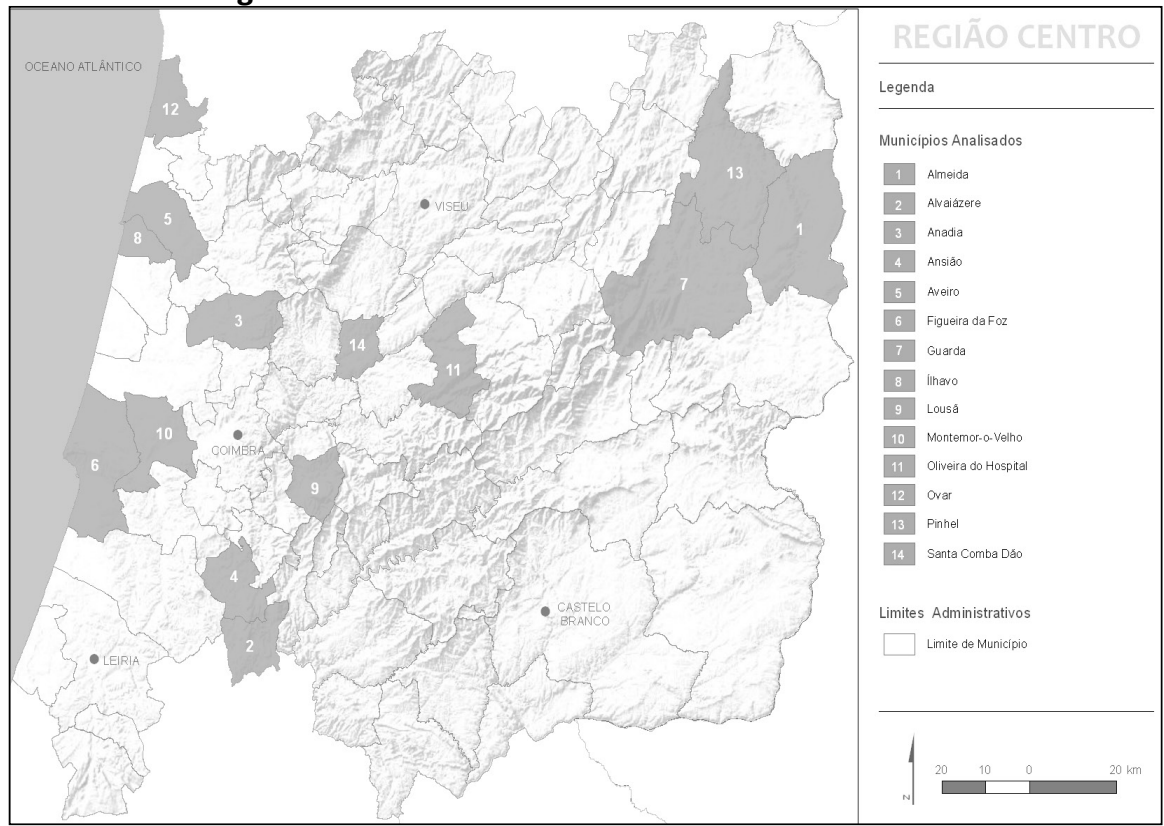

Fonte: Adaptações dos autores (2014).

\section{Emergência do planeamento estratégico na educação em Portugal}

Até aos anos 70, na educação (aliás, como em muitas outras áreas - saúde, território, economia, etc.) o tipo de planeamento em uso centrava-se na elaboração de planos. Esse instrumento de planeamento tradicional, dada a sua natureza, não conjeturava possibilidade de flexibilidade e de adaptação durante o processo de implementação. Assim, na sua abordagem clássica, o planeamento convencional baseava-se essencialmente na seleção de métodos e técnicas que permitiam alcançar os resultados desejáveis (eram utilizados instrumentos prescritivos, inflexíveis, não moldáveis à realidade e incapazes de lidar com a mudança), não valorizando o contexto em que ocorriam as ações. $\mathrm{O}$ objetivo consistia na aprovação do plano definitivo, que constituía um produto acabado e, por essa via, as dinâmicas territoriais eram desvalorizadas, bem como o fator incerteza.

Vivia-se, então, num tempo em que as práticas do planeamento tradicional 
se compaginavam com o Estado-providência, o qual era sustentado por políticas públicas redistributivas de tipo Keynesiano, dominado pelos valores da centralização e por uma visão burocrática e hierárquica do exercício do poder (STOER, 1986; SANTOS, 1993, 1994; AFONSO, 1997).

A partir dos anos 70, assiste-se a uma tendência para o abandono desta abordagem burocrática, assente num planeamento centralizado para soluções uniformes, e o início de um tipo de planeamento voltado para a complexidade, onde são exploradas outras metodologias mais adequadas à sociedade contemporânea. Planear deixa de ser uma atitude que perspetiva a evolução rumo a um fim desejado, previsível e orientado pela oferta e passa ao favorecimento de um entre os muitos outros possíveis (PERESTRELO, 2002), em que se equacionam as potencialidades e fraquezas do sistema, enquadradas num determinado contexto. Concomitantemente, o planeamento tradicional dá lugar ao planeamento estratégico (Quadro 1) que "surge como uma metodologia prospetiva que integra as múltiplas variáveis e determinantes" e cuja técnica assenta na hierarquização de "prioridades e faz a seleção das ações-chave para a mudança" (FERREIRA, 2005a, p.126).

A partir dessa visão, assiste-se, assim, à emergência do planeamento estratégico na educação, o qual procura compaginar, através de uma visão multidimensional (holística) e integrada, este com o paradigma da complexidade (MORIN, 1991; 1993) e da pós-modernidade (SANTOS, 1994). Conceptualmente, o planeamento estratégico promove uma visão para o território fundamentada num diagnóstico prospetivo e numa gestão de longo prazo. Baseia-se no mapear de futuros possíveis, na identificação de tendências e incertezas, e na antecipação de oportunidades e ameaças. Caracteriza-se pelo carácter multidisciplinar e participado, pela clara definição das funções e responsabilidades de cada nível de intervenção, por um bom suporte de informação, pela articulação entre a gestão e o planeamento e pela visão estratégica e flexibilidade (CABRAL; MARQUES, 1996; FERREIRA, 2005b).

Quadro 1 - Principais caraterísticas do Planeamento Tradicional e do Planeamento Estratégico 


\begin{tabular}{ll}
\hline Planeamento tradicional & Planeamento Estratégico \\
\hline - Sectorial & - Global e integrado \\
- Físico & - Diversas vertentes \\
- Normativo/Regulador & - Processual/Operacional \\
- Extrapolação de Tendências & - Prospetivo \\
- Tecnocrático & - Participativo \\
- Orientado pela Oferta & - Orientado pela Procura \\
- Rígido & - Flexível \\
\hline
\end{tabular}

Fonte: Adaptação dos autores baseado em Ferreira (2005a).

Tais características conduziram inevitavelmente a mudanças no nível dos instrumentos de planeamento e que são explicitadas através da valorização da preparação de políticas, estratégias e programas, isto em vez dos tradicionais planos. Daí a importância que é atribuída à negociação e à construção de consensos no decurso desse processo.

Com o aparecimento do planeamento estratégico, novos conceitos e instrumentos emergem. A abordagem estratégica territorial surge como um novo paradigma, o processo de planeamento sobrepõe-se ao plano, os instrumentos de execução ganham maior atenção, e a monitorização e a avaliação passam a ser indispensáveis. Estes novos conceitos e instrumentos foram inspiradores para algumas das mudanças que viriam a ocorrer, entre outras, no campo educativo, e aqui, em particular, no domínio do planeamento da rede escolar.

\subsection{Planeamento estratégico como "fator" de mudança na rede escolar}

Em Portugal, a partir do final dos anos 80 , já em pleno ciclo "reforma educativa" (GOMES, 1999), avolumam-se as análises das dimensões tradicionais das políticas e das práticas organizacionais e administrativas de tipo centralista e burocratizado (AFONSO, 1998; RUIVO, 2000; LIMA; AFONSO, 2002; BARROSO, 2004; FORMOSINHO, 2005) e aos desafios colocados à escola na transição pós-moderna (STOER, 1994; MAGALHÃES, 1998; GOMES 1999; TEODORO, 2001). Dessas análises ressalta a defesa de uma agenda educativa de tipo participativo e descentralizador (LIMA; 1995; 2004; BARROSO, 1998; PINHAL, 2004, 2005, 2006; PRATA, 2004; FERNANDES, 2004; 2005; FERREIRA, 2005b; MARTINS et al., 2006; COSME; TRINDADE, 2007; TRISTÃO, 2009; CRUZ, 2012) que permite criar condições para a consolidação 
de uma escola democrática.

É também nesta fase que emergem, com maior vigor, as críticas às limitações do paradigma tradicional de planeamento da educação, com incidência na rede escolar. Em alternativa, observa-se a defesa de um modelo de planeamento prospetivo, participado e descentralizado (FERNANDES, 1988; GABINETE DE ESTRATÉGIA E PLANEAMENTO, 1989a; 1989b, 1992) que tem em conta princípios de diversidade, complementaridade e flexibilidade dos equipamentos.

No início da década de 90, é a própria administração educativa (GEP, 1992a; 1992b) que, face aos problemas e carências com que se debatia a rede escolar no nível das regiões e dos municípios, passa a assumir a indispensabilidade de um planeamento da rede escolar que deveria ser moderno, inspirado na perspetiva e na planificação estratégica. Essa mudança é intrinsecamente acompanhada por outras não menos importantes: i) a passagem do planeamento da rede escolar baseada no conceito de "escola-edificio" para um planeamento assente no conceito de "escola-organização", em que a escola tende a "transformar-se cada vez mais num centro ou elo de uma rede dispersa de locais de ensino e de formação, e num espaço de múltiplas e diversas atividades de cariz comunitário" (FAZENDEIRO, 1992, p. 7475); ii) a escolha do território municipal como espaço privilegiado de planeamento que implica, entre outros, o reforço institucional entre os níveis central, regional e local da Administração; iii) uma programação estratégica de equipamentos subordinada a três princípios: diversidade de tipologias, flexibilidade de soluções e a complementaridade na gestão e utilização dos recursos; iv) necessidade de expansão no $3 .^{\circ}$ ciclo e racionalização da rede escolar, sobretudo no $1^{\circ}$ ciclo (MARTINS, 2000; CORDEIRO, 2008; CORDEIRO, 2011).

A Carta Escolar de responsabilidade municipal só veio a ter consagração legal no final da década de 90 ( art. $^{\circ} 19 .^{\circ}$ da Lei n. ${ }^{\circ}$ 159/99, de 14 de Setembro). Pretendia-se que partir de então, e isto no plano da descentralização educativa, progressivamente se viesse a assistir à passagem de uma regulação do poder

2 Com esta introdução do conceito de "escola-organização", o planeamento da rede "desloca-se de uma perspetiva de mera alocação de recursos, baseado na equação mais recursos = mais educação = mais igualdade de oportunidades para uma visão integrada em que a escola organização se articula com outras unidades de formação" (Gomes, 2005, p. 205). 
central, para uma regulação mais local, cujo objeto seriam as "cartas escolares municipais" a serem elaboradas pelas autarquias (BARROSO, 2003; PINHAL, 2004). Constatou-se, contudo, que a atribuição desta competência às autarquias não correspondeu a uma efetiva mobilização de objetivos e meios, já que o seu carácter não obrigatório e a inexistência de um pacote financeiro para a sua concretização, deixava antever o seu insucesso ${ }^{3}$.

Posteriormente, e com a publicação do Decreto-Lei 7/2003, veio a estabelecerse o quadro regulamentar do processo de elaboração e aprovação da Carta Educativa e os seus efeitos, processos que já há muito eram reclamados pelos municípios.

A sua consagração legal viria a assinalar, o início de uma nova fase do planeamento e reordenamento da rede escolar municipal, processo sem precedentes em Portugal. Tal fase encontra-se marcada pela afirmação do planeamento prospetivo, pelo protagonismo da dimensão local na construção das soluções, pela diversidade e pluralidade de propostas de reorganização e de distribuição territorial, pelo significativo volume financeiro disponibilizado para a construção e requalificação de escolas e, ainda, pelo encerramento de milhares de escolas de pequena dimensão.

Julga-se, porém, e mesmo podendo ser considerada como uma lógica de centralismo (o que não o é), que este momento do processo deveria ter sido precedido de um documento como o NUT III, o qual poderia, em muitos sectores, indicar alguns dos caminhos a serem seguidos a outra escala, e a proporcionar a possibilidade de se equacionar equipamentos de índole intermunicipal. Estes equipamentos funcionariam numa lógica de otimização de, por exemplo, recursos e de melhores soluções para milhares de alunos que residem em setores periféricos de muitos municípios. Estes documentos apenas tiveram o seu desenvolvimento alguns anos mais tarde (2008), e numa situação algo discutível, aliás já a jusante da aprovação e homologação da esmagadora maioria das "Cartas Educativas Municipais" (CORDEIRO, 2008; CORDEIRO 2011; CORDEIRO et al., 2012).

\section{3 "Construção" da Carta Educativa: do diagnóstico às soluções}

3 As informações factuais recolhidas durante a investigação junto dos catorze municípios demonstram que em todos os casos a Carta Escolar não chegou a ser elaborada, nem tão pouco equacionada. 
Não obstante a publicação de todo um conjunto de normativos que deveriam levar à realização da Carta Educativa, entre 2003 e 2005, dos cerca de 308 municípios, apenas 24 tinham elaborado a Carta Educativa (Rodrigues, 2010). Em face deste diagnóstico e da necessidade de concretização da política da "Escola a Tempo Inteiro", assistiu-se, nesse último ano, ao lançamento e concretização de um conjunto de medidas - políticas, administrativas e financeiras - que viriam a contribuir, decisivamente, para incrementar a elaboração das Cartas Educativas pelos municípios.

O Ministério da Educação encetou, nesse momento, uma série de ações, das quais se pode destacar o estabelecimento de protocolos com a Associação Nacional de Municípios Portugueses (ANMP), nos quais se fixaram novos prazos limites para a construção das Cartas Educativas, bem como a definição de normas e percentagens de financiamento estatal para a sua elaboração e a reformulação de critérios para o encerramento de escolas, até 10 e 20 alunos (Rodrigues, 2010), medidas essas que tinham com principais objetivos impulsionar os municípios a elaborarem as suas Cartas Educativas, ao mesmo tempo que serviam de instrumento para alcançar os níveis de eficácia, eficiência e qualidade da rede escolar pretendidos pela tutela.

Não obstante a retórica política da territorialização educativa que acompanhou tais medidas, o processo de elaboração da Carta Educativa foi marcado pelo confronto ou justaposição entre um movimento bottomup (de baixo para cima), protagonizado pelo envolvimento dos atores locais na discussão e aprovação das soluções de planeamento da rede escolar, e o movimento top-down (de cima para baixo) de encerramento de escolas pelo poder central. As tensões geradas entre as práticas de descentralização da educação (FORMOSINHO, 2005; NETO-MENDES, 2007) e as estratégias de recentralização das periferias (LIMA, 1995; LIMA, 2007), presentes nos dois movimentos mencionados, ilustram a presença de um Estado dual, visível na coabitação e sobreposição de dois modelos de regulação ${ }^{4}$.

A complexidade, hibridismo e as contradições presentes em processos de descentralização, como é o caso, aliados às "desconfianças" históricas que acompanham o desenrolar do municipalismo em Portugal, contribuíram

4 "De um lado, modelo de regulação burocrático "controlador e regulamentador, que exerce a sua ação com «mãos de ferro»", procurando assegurar, pelo centralismo e pela hierarquização dos processos de decisão e execução, a obediência a regras universais"; e do outro lado, "o modelo de governança que faz apelo à negociação e à participação dos diferentes atores, no quadro de uma regulação policentrada em que o controlo já não se faz pela obediência a normas e regulamentos, mas pela obtenção de determinados resultados" (Barroso, 2011: 14). 
para que o processo de adesão dos municípios à Carta Educativa não se tenha desenrolado da mesma maneira entre regiões, entre municípios da mesma região e até dentro da mesma NUT III (CORDEIRO, 2011). $\mathrm{O}$ relatório internacional sobre a política educativa para o $1^{\circ} \mathrm{CEB}^{5}$ (MATTHEWS et al., 2009) assinala que a adesão dos municípios a este instrumento de planeamento e reorganização da rede escolar foi variável, sublinhando, por exemplo, que o processo na região norte evoluiu mais rapidamente que na região centro.

Aliás, e no contexto da região Centro, e tomando como indicadores a data/ ano de aprovação da Carta Educativa pelas Assembleias Municipais, a análise permitiu identificar e associar os municípios em três grupos - os entusiastas, os "cumpridores" e os "resistentes" - consoante a maior ou menor celeridade com que avançou para o processo de elaboração da Carta Educativa. Os municípios entusiastas foram os primeiros a avançar para a elaboração porque acreditavam na pertinência do instrumento e não tinham medo da mudança; o grupo dos cumpridores avançaram mais lentamente, mas fizeram-no principalmente porque era uma imposição política-legal para terem direito ao financiamento; por último, os resistentes aderiram ao processo mais tardiamente, arrastados pelas circunstâncias (encerramento de escolas, pressão estatal e das comunidades locais para criarem condições para a implementação da Escola a Tempo Inteiro, entre outras).

\subsection{Diagnóstico dos problemas da rede escolar, em contextos municipais}

O processo da Carta Educativa Municipal passa por três fases fundamentais: elaboração, aprovação (local e central) e execução. No caso da elaboração, coube ao município proceder ao seu desenvolvimento, através de recurso aos seus próprios técnicos ou a entidades externas (empresas, universidades e associações de municípios, foram os exemplos mais frequentes), traduzindo-se a Carta Educativa por um documento, no qual se devia proceder à compreensão das realidades territoriais e socioeconómicas, das respetivas dinâmicas de oferta $v s$ procura, a que se deveriam seguir uma leitura prospetiva e a formulação de propostas de intervenção a curto e médio prazo, observando-se momentos distintos na aprovação e

$5 \mathrm{O} 1^{\circ} \mathrm{Ciclo}$ do Ensino Básico $\left(1^{\circ} \mathrm{CEB}\right)$ corresponde ao ensino Primário, ou seja, aos quatro primeiros anos do ensino obrigatório (crianças com idades compreendidas entre os 6 e os 9 anos). 
homologação das mesmas.

A partir de uma análise de catorze municípios com localizações territoriais, dimensões geográficas e demográficas tão distintas, o presente artigo incidiu especialmente em apenas quatro deles, permitindo verificar que, de um modo geral, as Cartas Educativas foram elaboradas no respeito de um conjunto de critérios e passos metodológicos, os quais, entretanto, iam sendo definidos pela Tutela (MARTINS, 2000) e que podem ser identificados em oito eixos principais: (1) princípios orientadores; (2) objetivos estratégicos; (3) enquadramento territorial e geográfico; (4) caracterização socioeconómica; (5) caracterização e evolução do sistema educativo municipal; diagnóstico estratégico; (7) propostas de reordenamento da rede escolar; (8) plano financeiro e periodização.

Da análise dos dados dos eixos relativos à caracterização e diagnóstico traçados sobre a rede escolar, no conjunto dos municípios, em particular na que diz respeito à do $1^{\circ}$ Ciclo do ensino básico, sobressaem, com maior ou menor evidência, com mais ou menos detalhe, os problemas identificados desde os anos 80, muito relacionados com o modelo de planeamento anteriormente efetuado: em zonas rurais e de baixa intensidade, a existência de um número elevado de escolas de pequena dimensão, geograficamente dispersas e desprovidas de outros espaços que não as salas de aula; nas zonas mais urbanas e de alta densidade a existência de um número considerável de escolas a funcionar em regime duplo, e algumas delas sem capacidade para fazer face à procura, dadas as elevadas taxas de sobreocupação.

A incidência destes problemas não é, assim, vivida da mesma maneira pelos diferentes municípios em análise (cf. Figura 1): uns casos estão confrontados, sobretudo, com os problemas característicos das zonas rurais, ou seja, dos territórios de baixa densidade; outros apresentam a sobrelotação das escolas e a dificuldade de fazer face à procura de maior dimensão problemática, muito por força de um crescimento urbano; (3) casos há, ainda, em que os problemas da dispersão da rede e da sobrelotação das escolas assumem preocupações semelhantes, conforme os sectores dos seus territórios.

Um dos bons exemplos do primeiro grupo (1) é o do Município de Almeida, o qual se tem vindo a debater, nas últimas décadas, com um decréscimo significativo da população residente, uma vez que, num período de 50 anos, 
perdeu um valor superior à metade da sua população \{CMAlm, 2007\}. Deste facto, resulta uma significativa diminuição da população em idade escolar, a desertificação populacional de uma boa parte do seu território (associado a um significativo envelhecimento) e a consolidação de um território fortemente bipolarizado, o reflexo dessa bipolarização, encerrou 9 EB1 $^{6}$ entre 2004 e 2006 \{CMAlm, 2007, p. 58\}. Em 2006/2007, a rede educativa municipal passou a ser constituída por três jardim de infância, nove escolas do $1^{\circ}$ Ciclo e duas EB2, $3^{7}$, encontrando-se territorializada em apenas 10 das 29 freguesias (Figura 2). Dado o nível de procura nalguns estabelecimentos tender a reduzir-se, como refere o diagnóstico da Carta Educativa \{CMAlm, 2007, p. 59\}, a bipolarização e a contração da rede escolar, em especial as do $1^{\circ}$ Ciclo, tendem a acentuar-se (cfr. figura 2 ).

De facto, a proposta de reorganização da rede educativa constante na Carta Educativa de Almeida preconiza o acentuar do número de zonas do território municipal sem qualquer oferta escolar, através da proposta de encerramento de quatro jardins de infância e duas escolas do $1^{\circ}$ Ciclo e, antecipando mesmo que a "médio prazo toda a oferta de ensino no concelho fique concentrada nas duas principais freguesias ${ }^{8}$ do concelho - Almeida e Vilar Formoso - \{CMAlm, 2007, p. 148\}. Simultaneamente, o pólo de Vilar Formoso acentua a sua capacidade de oferta educativa, sendo mesmo de referir que as duas EB 2,3/ $\mathrm{S}^{9}$ passam a assumir-se como espaços escolares de acolhimento também de alunos do $1^{\circ} \mathrm{CEB}$.

6 Escolas do Ensino Básico do $1^{\circ}$ Ciclo (acolhem alunos dos quatro primeiros anos de escolaridade).

7 Escolas do ensino Básico que acolhem alunos de idades compreendidas entre os 10 e 14 anos, e que correspondem a dois níveis de ensino $-2^{\circ}$, com o $5^{\circ}$ e $6^{\circ}$ anos de escolaridade e o $3^{\circ}$ ciclo que integra os $7^{\circ}, 8^{\circ}$ e $9^{\circ}$ anos.

8 São territórios de pequena dimensão, que, normalmente, se apresentam como subdivisões dos municípios em Portugal e com órgãos eleitos, sendo administrados por um Presidente da Junta da Freguesia, ainda que sem grande poder autonómico relativamente ao Município.

9 Escolas de Ensino Básico de $2^{\circ}$ e $3^{\circ}$ Ciclos (alunos dos 10 aos 14 anos) com o Ensino Secundário (acolhem alunos do $10^{\circ}$ ao $12^{\circ}$ anos). 


\section{Figura 2 - Análise comparativa entre o momento inicial e final da reorganização} da rede educativa do Município de Almeida

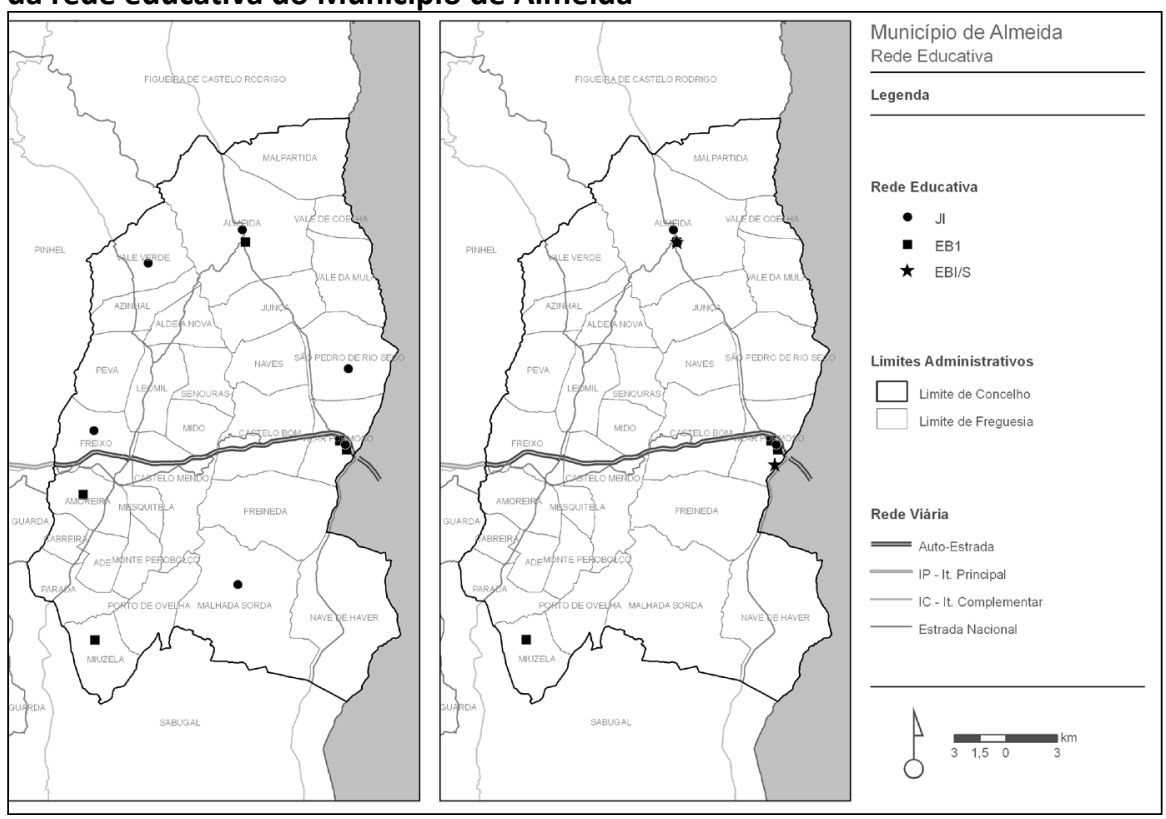

Fonte: Adaptações dos autores (2014).

Ao contrário do Município anterior, que regista um decréscimo da população escolar e se debate com o aumento do número de escolas do $1^{\circ}$ Ciclo com um reduzido número de alunos, características das próprias zonas rurais de baixa densidade, o Município de Ovar confronta-se, especialmente, com os problemas próprios das zonas urbanas de alta densidade.

De facto, Ovar registou, a partir da década de 1960-70, "um crescimento demográfico pouco comum [...] e que tornou completamente desajustada a rede educativa herdada do Plano dos Centenários" (CÂMARA MUNICIPAL DE OVAR, 2007, p. 304). Como consequência desse crescimento demográfico, nas décadas de 80 e de 90 , muitos estabelecimentos tiveram que ser construídos de novo e, simultaneamente houve necessidade de "realização de obras de ampliação de muitos estabelecimentos de menor dimensão (CÂMARA MUNICIPAL DE OVAR, 2007, p. 304). Ainda assim, em 2005/06, a rede escolar do $1^{\circ}$ Ciclo, por "força de uma diferente relação entre o número de salas de aula disponíveis" era a que apresentava a "taxa de ocupação mais elevada, de 
111,58\%”, em resultado da inadequação da rede educativa em várias freguesias, face à elevada procura educativa e ao consequente desdobramento de horário (CÂMARA MUNICIPAL DE OVAR, 2007, p. 284-334).

Nesse cenário, e apesar da existência de escolas de pequena dimensão (na maioria dos casos com imensas vagas por ocupar), é a adequação da oferta à procura das escolas sobreocupadas que surge como principal problema a resolver. Como resposta à falta de capacidade de oferta face à procura, e às caraterísticas do equipamento em termos de espaços que a "escola a tempo inteiro" exigia num primeiro momento, a proposta de reorganização (Figura 3) incide na necessidade de edificação de novos estabelecimentos - doze Centros Escolares - a sua maioria a implantar nos dois principais aglomerados populacionais: Ovar e Esmoriz.

Em suma, os diagnósticos traçados nas cartas educativas destes dois municípios - Almeida e Ovar - mostram alguns dos problemas que a rede escolar do $1^{\circ}$ Ciclo apresentava, bem como das diferentes incidências observadas no contexto municipal, apesar dos aspetos comuns que, por vezes, os atravessam. Por isso, a existência de maior ou menor número de escolas de reduzida dimensão no contexto da rede escolar municipal, o grau de incidência de escolas sobrelotadas ou a conjugação destes dois problemas colocam há longos anos desafios diferentes na definição dos critérios e nas propostas de reorganização da rede escolar.

\section{Figura 3 - Análise comparativa entre os momentos inicial e final da} Reorganização da rede educativa do Município de Ovar

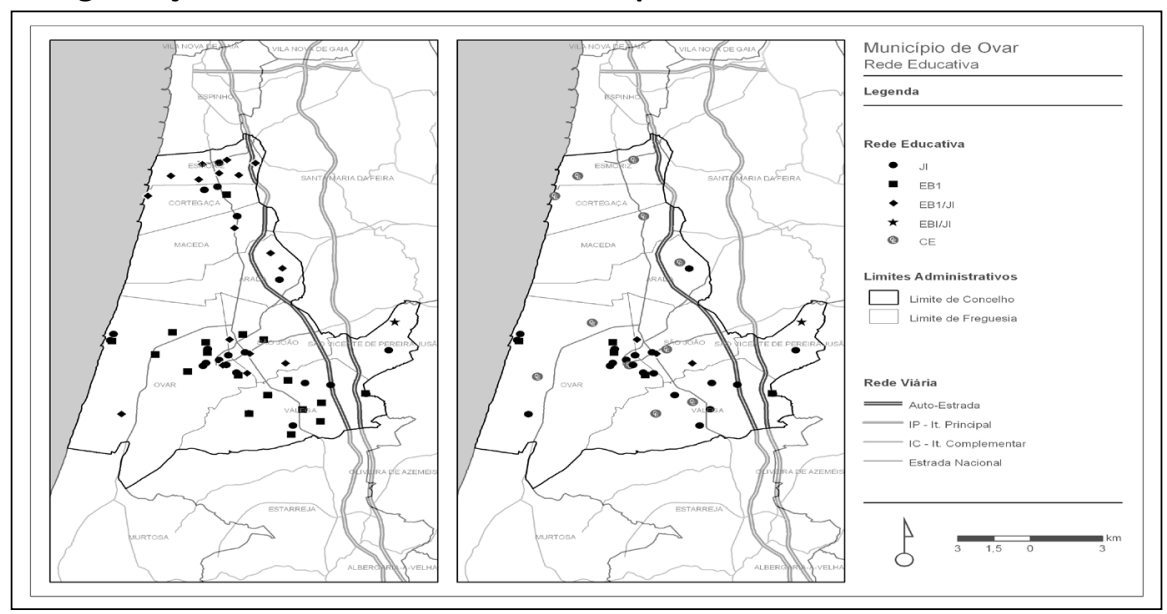

Fonte: Adaptações dos autores (2014). 


\subsection{Propostas de reordenamento da rede escolar municipal: tendências}

Da análise de conteúdo efetuada sobre as soluções de reordenamento da rede escolar $\left(1^{\circ}\right.$ Ciclo e Pré-escolar) contidas nas Cartas Educativas do estudo, e tendo em conta as dimensões de análise - encerramento de escolas do $1^{\circ}$ Ciclo; concentração da rede; distribuição espacial da rede escolar no território municipal; diversidade de tipologias - tornou-se possível identificar três tipos de soluções prevalentes de reordenamento: A) "decretado", quando as soluções de reordenamento da rede escolar propostas têm total correspondência com as defendidas pelo Estado central; B) "conciliação", quando as soluções encontradas tendem a conciliar as soluções emanadas pelo Estado e as defendidas pelo município; e C) “ comunitário", quando as soluções encontradas tendem a dar resposta apenas às reivindicações locais ${ }^{10}$.

A) Reordenamento de "tipo decretado". É nos municípios de Santa Comba Dão e Almeida onde as propostas de reordenamento de "tipo decretado" são mais percetíveis. Percebe-se pela análise das propostas uma nítida correspondência com os objetivos técnico-políticos que eram defendidos pelo poder central. Deste modo, as soluções do "tipo decretado" estão sustentadas em lógicas de predomínio técnico-administrativas e pressupõem uma imbricação políticonormativa das soluções das periferias às políticas decididas pelo centro. O papel desempenhado pelo município na definição das soluções de reordenamento da rede escolar tipo decretado é remetido para um mero intérprete local das medidas e orientações definidas centralmente. Concomitantemente, constata-se a existência de microrregulação local ${ }^{11}$ rendida aos méritos de uma proposta tecnicamente competente, eficaz e eficiente.

É facilmente detetável os elevados níveis de retração da rede escolar previstos, e a prevalência do Centro Escolar (enquanto tipologia preferida pelo Ministério da Educação e adotada pelo município) como solução preponderante para a resolução dos problemas inerentes à rede escolar do $1^{\circ}$ Ciclo e à concretização da Escola a Tempo Inteiro. Os elevados níveis de eficácia e eficiência decorrentes das soluções

10 Neste contexto, parece ser de referir que as soluções do $1^{\circ}$ tipo - decretado - encontram-se compaginadas com lógicas de predomínio técnico-administrativo, enquanto que as de segundo e terceiro tipos - conciliação e comunitário - as lógicas são predominantemente políticas e/ou comunitárias.

11 A microregulação local é aqui entendida como o "processo de coordenação da ação dos atores no terreno que resulta do confronto, interação, negociação ou compromisso de diferentes interesses, lógicas, racionalidades e estratégias em presença". 
propostas são, também, sinalizadores deste tipo de reordenamento. Contudo, as soluções previstas nas Cartas Educativas destes municípios não deixam de refletir, também, muitas das características morfológicas dos seus territórios (por norma, aplanados, logo sem grandes constrangimentos à mobilidade intermunicipal).

Do conjunto dos municípios analisados, um deles ressalta pela objetividade da sua reorganização. O Município de Santa Comba Dão (Figura 4) que, no ano letivo 2005/2006, apresentava uma rede escolar composta por um total de 33 estabelecimentos de ensino, dos quais 13 integravam a rede da Educação Pré-escolar e 20 do $1^{\circ}$ Ciclo (CÂMARA MUNICIPAL DE SANTACOMBADÃO, 2007, p.87). Da compaginação desta realidade com as projeções e os critérios de reordenamento estabelecidos pelo Ministério da Educação, a proposta de reorganização apontava para: criação de três territórios educativos, com o encerramento da totalidade das EB1's, mas com a manutenção parcial da rede de jardim de infância, considerando assim a filosofia subjacente à reorganização - " $1{ }^{\circ} C E B$ de qualidade e Educação Préescolar de Proximidade" (CÂMARA MUNICIPAL DE SANTA COMBA DÃO, 2007, p. 296). Nesse sentido, as soluções (Figura 4) passam pelo encerramento progressivo das vinte escolas do $1^{\circ}$ Ciclo e a construção de três centros escolares, de tipologia EB1/JI. No final da reorganização, as escolas do $1^{\circ}$ Ciclo são substituídas por Centros Escolares com maior capacidade e com outras valências.

\section{Figura 4 - Analise comparativa entre os momentos inicial e final da} reorganização da rede educativa do município de Santa Comba Dão

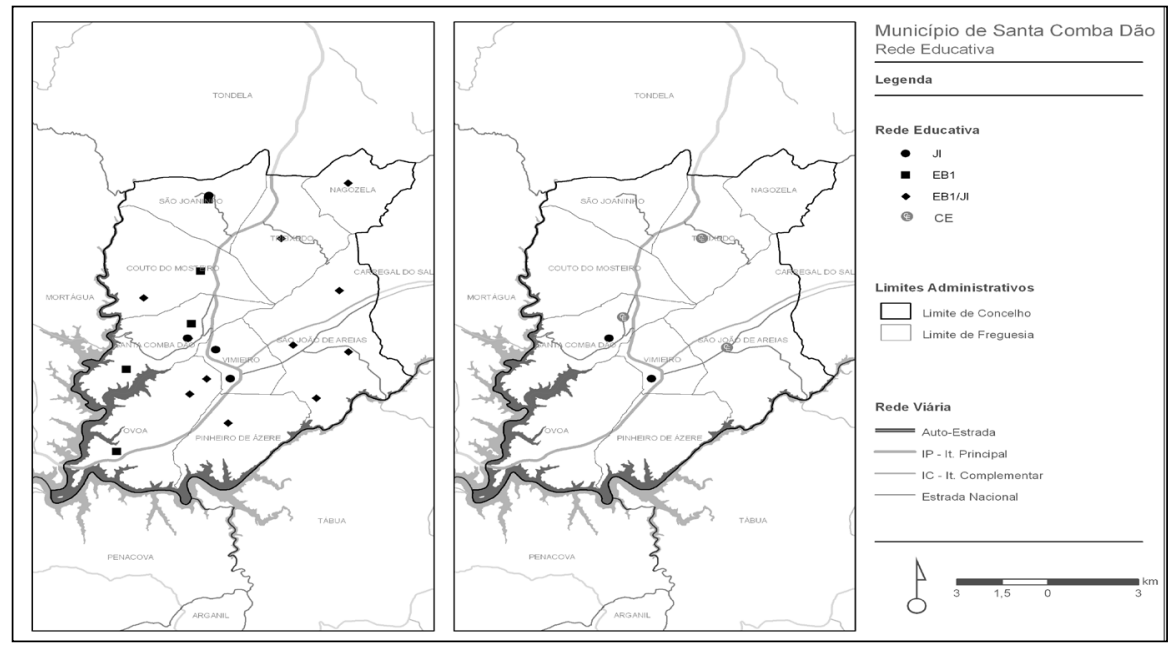

Fonte: Adaptações dos autores (2014). 
No que respeita à localização dos centros escolares, observa-se a preocupação em termos de "centralidade e distância casa-escola (...) no sentido de diminuir as dificuldades sentidas pela Autarquia no assegurar dos transportes escolares" (CÂMARA MUNICIPAL DE SANTA COMBA DÃO, 2007, p. 383). No entanto, com esta proposta, há freguesias que deixam de ter oferta para o $1^{\circ}$ Ciclo, situação que conduz a um aumento significativo do número de alunos em mobilidade, embora deva ser referido que são territórios de baixa densidade e com um número de nascimentos relativamente reduzido.

Entre os resultados mais visíveis do reordenamento do "tipo decretado" do Município de Santa Comba Dão (mas que pode ilustrar as restantes propostas deste tipo), encontram-se o encerramento de um número expressivo de escolas; a opção por uma rede escolar fortemente concentrada; o aumento significativo do número de alunos em mobilidade; e a aposta no centro escolar como solução privilegiada de reordenamento (escala e qualidade), o qual permite, com a sua total implementação, a criação de condições para que todas as crianças do território apresentem condições de igualdade no acesso ao ensino ${ }^{12}$.

B) Reordenamento do "tipo conciliação". A par das soluções de reordenamento da rede escolar que tendem a compaginar-se com as medidas decretadas, como as acabadas de analisar, detetam-se casos em que os municípios procuraram soluções de "conciliação" que tendem a harmonizar os objetivos do Estado Central com o contexto e especificidades do próprio território municipal. Aqui, as soluções de reorganização são construídas numa arena política de baixa intensidade ou mesmo mitigada, onde os municípios e o Estado procuram, através de um processo compósito de perdas e ganhos, chegar a soluções que satisfaçam tanto o centro como a periferia. Assim, o município é remetido a um papel de coautor das soluções da rede escolar para o seu território, ao assumir que as soluções encontradas são as "possíveis" e não as "desejadas" ou mesmo as "necessárias".

A conciliação das soluções é visível nas Cartas Educativas cujas propostas assentam: na coexistência de uma rede escolar composta por estabelecimentos com várias tipologias para o $1^{\circ}$ Ciclo e Pré-escolar - centros escolares (EB1/ JI); escolas do $1^{\circ}$ Ciclo (EB1) e jardins de infância (JI); na concretização do encerramento de escolas com baixa frequência compaginada com a manutenção

12 A implementação desta proposta de reorganização foi efetuada a 100\%, sendo de realçar que o grau de satisfação de todos os atores é extremamente elevado. 
de uma escola por freguesia e; na definição de limites máximos para a dimensão dos centros escolares e para as distância-tempo a percorrer entre casa e a escola.

O resultado da reorganização do tipo conciliação espelha a procura do município em harmonizar os critérios de racionalidade e de qualidade defendidos pela Tutela, com uma rede escolar de malha menos larga e, por isso, mais próxima das comunidades locais e mais consentânea com o defendido pelo poder local. Entre os municípios cujas propostas soluções de reordenamento se inscrevem no tipo conciliação destaca-se, na amostra de estudo, o já anteriormente analisado município de Ovar (cf. Figura 3).

C) Reorganização do "tipo comunitário". Neste tipo de reorganização, ao contrário do que se verifica na reorganização decretada, são os interesses políticos e sociais locais que se sobrepõem, num complexo jogo de estratégias, negociações e ações protagonizadas pelos vários atores locais. As soluções de reorganização da rede escolar, neste caso, resultam de tensões políticas vincadas entre o município e o Estado, onde a força e influência política local procuram secundarizar ou mesmo contrariar a força político-normativa do poder central. Aqui imperam as lógicas comunitárias dos administrados face às lógicas institucionais dos administradores.

O município escolhido para ilustrar o reordenamento tipo comunitário é o da Figueira da Foz, território do litoral, e onde o contraste observado entre um centro urbano (alta densidade) e um mundo rural (baixa densidade), reflete-se $a$ posteriori em muitas das ambiguidades que um poder político frágil transmite para um planeamento estratégico. É possível observar que as diferenças entre a fase inicial e a fase final da reorganização da rede escolar são substancialmente menos significativas do que aquelas que foram detetadas nas reorganizações decretadas e de conciliação, e isto muito por força de uma oposição acérrima do poder local, designadamente das freguesias.

O Município da Figueira da Foz é caracterizado pelos contrastes observados no nível da demografia, da mobilidade e da hierarquização dos lugares: apresenta "um mundo urbano, que se tem desenvolvido ao ritmo das regiões litorais", e, numa dinâmica oposta, também tem "um mundo rural" a perder população e com elevados índices de envelhecimento (CÂMARA MUNICIPAL DE FIGUEIRA DA FOZ, 2006, p. 407). 
Em 2005/2006, a partir de um total de 82 estabelecimentos de ensino (58 escolas do $1^{\circ}$ Ciclo e 24 jardins de infância), a reorganização da rede educativa do município da Figueira da Foz propõe a definição de dez "territórios educativos", os quais acabam por determinar a "localização dos diferentes Centros Educativos ou mesmo «Escolas de Freguesia» [...] encontrando-se alguns deles a serem servidos por diferentes escolas em simultâneo" (CÂMARA MUNICIPAL DE FIGUEIRA DA FOZ, 2006, p. 408). Na fase final da reorganização (Figura 5) prevê-se a existência de 9 centros escolares, mas que, na sua maioria, deveriam ser o resultado de obras de ampliação/ requalificação de escolas já existentes (sendo um deles de cariz intermunicipal), a remodelação de 2 EB1 e a manutenção de 4 EB1. Como resultado, as soluções de reorganização são de baixa intensidade, ou seja, a distribuição geográfica da rede escolar sofre poucas alterações (exemplo, uma escola por Freguesia); os parâmetros de escala e de requalificação são menos expressivos; há a manutenção de escolas com poucos alunos; a aposta é a manutenção de uma rede de proximidade; um reduzido aumento de alunos em mobilidade; e a opção pelo centro escolar é exceção.

Figura 5 - Análise comparativa entre as fases inicial e final da reorganização da rede educativa do município da Figueira da Foz

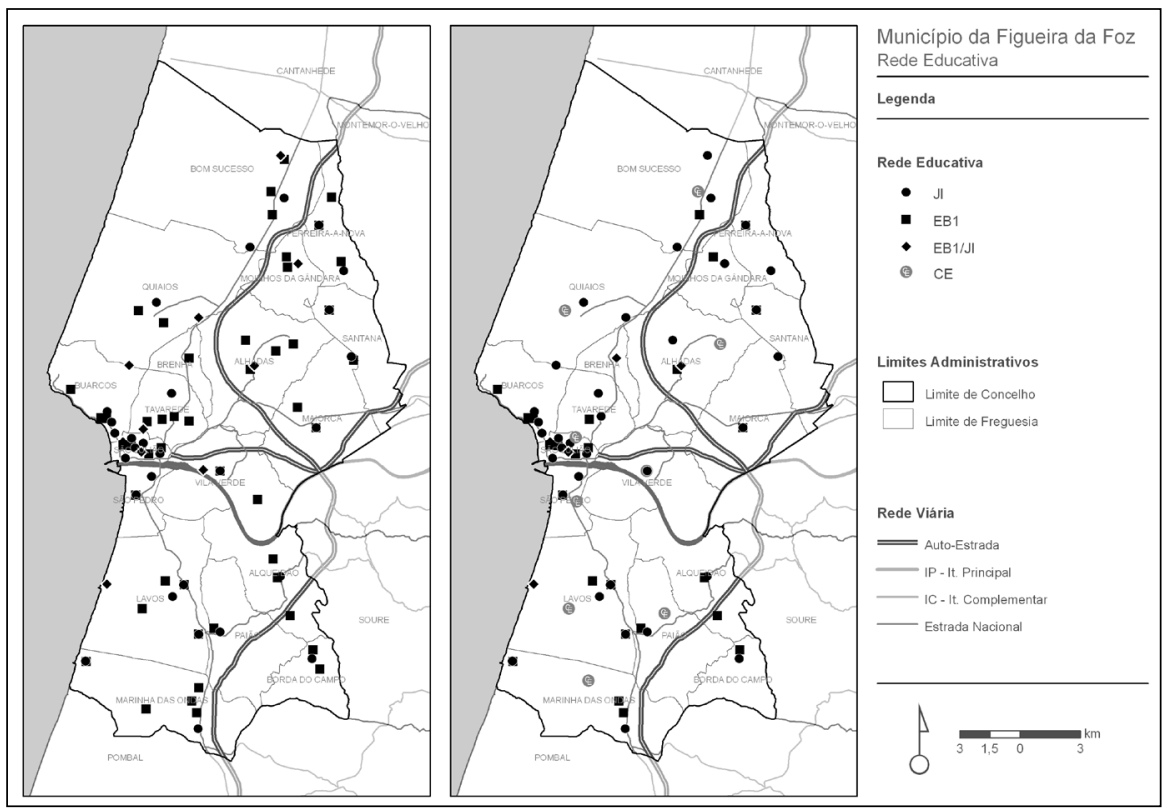

Fonte: Adaptações dos autores (2014). 
Passados seis anos sobre a aprovação da Carta Educativa Municipal da Figueira da Foz, apenas foi construído de raiz um Centro Escolar (o urbano, e neste caso com o encerramento das pequenas escolas deste setor), observando-se por oposição trabalhos de remodelação de um número significativo de EB1's. Em suma, o resultado da concretização da proposta de reorganização, e à exceção do caso do centro urbano, vai no sentido da manutenção de uma rede escolar de proximidade, sendo que as alterações da rede escolar (requalificação, ampliação e reconversão) foram sempre efetuadas a partir dos edifícios existentes, as quais se cingiram à construção/remodelação de salas de aula, não se tendo observado intervenções para equipar as escolas do $1^{\circ}$ ciclo e jardim de infância com espaços complementares - cantina, biblioteca, espaço desportivo, etc -, razão pela qual o encerramento de escolas se apresenta muito diminuto.

É possível verificar neste tipo de "reorganização" a prevalência de soluções que correspondem maioritariamente às reivindicações do mosaico de atores locais, sobrepondo-se ou ignorando, em larga medida, os critérios e objetivos definidos centralmente. Ao mesmo tempo, a reorganização da rede escolar proposta mantém no mundo rural, a malha de escolas herdadas do Plano dos Centenários, e isto cerca de meio século após a sua implementação, e apesar das substanciais transformações entretanto observadas.

Passados seis/sete anos sobre a aprovação e homologação destas Cartas Educativas com reorganizações de tipo comunitário, observa-se a necessidade premente da sua revisão, agora com o refletir de lógicas de planeamento estratégico, já que muitas delas assumiram-se como documentos redutores que não se compaginam com as necessidades da educação deste início do Século XXI.

Após as apreciações elaboradas sobre as soluções de reorganização da rede educativa, importa sublinhar que as soluções encontradas pelos diversos municípios não se esgotam nos três "tipos" aqui identificados, existindo cartas educativas que espelham soluções híbridas onde as decisões não seguem um padrão inequívoco.

\section{Algumas reflexões finais}

Durante as duas últimas décadas do século $\mathrm{XX}$, a rede escolar portuguesa debateu-se com graves desequilíbrios entre a oferta e a procura e que se vieram 
a traduzir num aparente paradoxo: "alunos a menos" e "escolas a mais" em territórios de baixa densidade, em geral, rurais e do interior, por oposição à existência de "alunos a mais" e "escolas menos" em territórios de alta densidade, normalmente, urbanos e do litoral. Fruto de um planeamento de cariz centralizado e burocrático, quase sempre incapaz de olhar prospectivamente as alterações societais, a desconformidade da rede escolar existente passou ser pensada, nos finais do século XX, através da adoção de novas metodologias de planeamento e de políticas de aprofundamento da descentralização educativa. Neste sentido, as Cartas Educativas apareceram com um instrumento necessário à tomada de consciência e à responsabilização dos poderes municipais, convocando-os a pensar a rede escolar em face das novas realidades demográficas e das exigências educacionais do século XXI. Apesar de nem tudo ter corrido como se desejava, não há dúvida de que o processo que levou à elaboração e à aprovação das Cartas Educativas promoveu uma dinâmica de discussão e um planeamento estratégico que inúmeras vezes esteve na base de uma efetiva reorganização da rede escolar. Nesse sentido, os resultados da investigação avocados para este estudo, assim como os exemplos patentes neste artigo, permitem atestar a passagem de um planeamento de caraterísticas centralizadoras a um planeamento estratégico e descentralizado, pautado por lógicas municipais diferenciadas que procuraram encontrar, para cada um dos territórios, as soluções que os atores locais julgaram ser as mais adequadas. Não obstante a singularidade de cada uma das Cartas Educativas e respetivos territórios, o artigo permite identificar a existência de três principais tendências de reordenamento que oscilam entre propostas de pendor "racionalizador" e "comunitário". De qualquer modo, é possível ver que este processo de reordenamento da rede escolar deu bastante flexibilidade à participação e à tomada de decisões dos atores locais, embora tenham sido sujeitas e, até, condicionadas, pelo poder supervisor de que o Estado é detentor. Mas o estudo também mostra a ambiguidade estratégica presente nas decisões dos poderes municipais, que tanto podem corresponder mais aos propósitos do governo nacional como podem tender a ceder às pressões que, por motivos mais ou menos razoáveis, membros influentes nos pequenos aglomerados populacionais, conseguem impor. O processo relativo à elaboração das Cartas Educativas evidencia a dificuldade da mudança de paradigma na planificação da rede escolar, que resulta tanto da perspetiva demasiado racionalizadora (centrada no fechar de escolas com poucos alunos) do poder central, como da dificuldade do poder municipal pensar a educação no quadro de um desenvolvimento sustentado do seu território. 


\section{Referências}

AFONSO, A. Para a configuração do Estado-providência na educação em Portugal, 1985-1995. Educação, Sociedade e Culturas, Porto, n. 7, 131-156, 1997.

Políticas Educativas e avaliação Educacional. Para uma análise sociológica da reforma educativa em Portugal (1985-1995). Tese (Doutorado)Sociologia da Educação, Universidade do Minho, Braga, 1998.

BARROSO, J. Descentralização e autonomia: devolver o sentido cívico e comunitário à escola pública. Colóquio: educação e sociedade, [S.1.], n. 4, p. 32-58, 1998.

A "escolha da escola" como processo de regulação: integração ou selecção social? In: BARROSO, J. (Org.). A escola pública: regulação, desregulação e privatização. Porto: Edições Asa, 2003, p. 79-110.

A regulação da educação como processo compósito: tendências e desafios. In: COSTA, J. et al. (Org.). Politicas e Gestão Local da Educação. Aveiro: Universidade de Aveiro, 2004, p. 9-22.

CABRAL, J.; MARQUES, T. Do planeamento estratégico ao desenvolvimento sustentável: experiência em Portugal. Inforgeo, [S.1.], n. 11, p. 107-116, 1996.

CÂMARA MUNICIPAL DE OVAR. Carta Educativa de Ovar. Coimbra: PensarTerritório, Lda; Câmara Municipal de Ovar, 2007.

CÂMARA MUNICIPAL DE SANTA COMBA DÃO. Carta Educativa do Município de Santa. Coimbra: Comba Dão; CMSD/PensarTerritório, 2007.

CÂMARA MUNICIPAL DE FIGUEIRA DA FOZ. Carta Educativa da Figueira da Foz. Coimbra : Faculdade de Letras da Universidade de Coimbra, 2006.

COSME, A.; TRINDADE, R. Escola a Tempo Inteiro: escola para que te quero?. Porto: Profedições, 2007.

CORDEIRO, A. M. Reorganização da rede escolar. Boletim dos Professores: Ministério da Educação, [S.1], n. 20, p. 2-3, 2011. 
CORDEIRO, A. M. Reorganização do Parque Escolar por NUT III Pinhal Interior Norte. Coimbra: FLUC/GEPE, 2008. (Relatório).

CORDEIRO, A. M; MARTINS, H. A Carta Educativa Municipal como instrumento estratégico de reorganização da rede educativa: tendências de mudança. Cadernos de Geografia, Coimbra, n. 12, p. 30-31, 2012.

CORDEIRO A. M.; SANTOS, L.; CARIDADE, P. A Reorganização do Parque Escolar Nacional e a importância das componentes geográficas na metodologia adotada. Cadernos de Geografia, Coimbra, n. 1, p. 30-31, 2012.

CRUZ, C. Conselhos Municipais de Educação: política educativa e acção pública. Tese (Doutorado)-Ciências da Educação, Universidade de Lisboa, Lisboa, 2012.

FAZENDEIRO, A. Carta Escolar da Região Alentejo: GEP. Ministério da Educação: Lisboa, 1992. p. 11-22.

FERNANDES, A. A distribuição de competências entre a administração central, regional, local e institucional da educação escolar segundo a Lei de bases do sistema educativo. In: COMISSÃO DE REFORMA DO SISTEMA EDUCATIVO (Proposta Global de Reforma: Relatório Final). Lisboa: Ministério da Educação, 1988.

FERNANDES, A. Município, cidade e territorialização educativa”. In: COSTA, J. et al. (Org.). Políticas e gestão local da educação. Aveiro: Universidade de Aveiro, 2004. p. 35-43.

FERNANDES, A. Contextos de intervenção educativa local e a experiência dos municípios portugueses. In: J. FORMOSINHO, J. et al. (Org.). A administração da Educação: lógicas burocráticas e lógicas de mediação. Porto: Edições Asa, 2005. p. 193-224.

FERNANDES, A. O município e a instrução em Portugal no século XIX. Centralização e descentralização na administração da escola de interesse público. In: FORMOSINHO, J. et al. (Org.) A administração da Educação: lógicas burocráticas e lógicas de mediação. Porto: Edições Asa, 2005. p.13-52. 
. Gestão estratégica de cidades e regiões. Lisboa: Fundação Calouste Gulbenkian, 2005a.

FERREIRA, F. I. O Local em Educação: animação, gestão e parcerias. Lisboa: Fundação Calouste Gulbenkian , 2005b.

FORMOSINHO, J. A evolução do modelo de administração da escola de interesse público em Portugal (1926-86). In: FORMOSINHO, J. et al. (Org.) A administração da Educação: lógicas burocráticas e lógicas de mediação. Porto: Edições Asa, 2005. p. 91-114.

GABINETE DE ESTRATÉGIA E PLANEAMENTO. Primeira contribuição para a Carta escolar. Lisboa: Ministério da Educação, 1989a.

. Segunda contribuição para a Carta escolar. Lisboa: Ministério da Educação, 1989b.

. Carta escolar da Região Centro. Lisboa: Ministério da Educação, 1992.

GOMES, R. 25 anos depois: expansão e crise da escola de massas em Portugal. Educação, Sociedade e Culturas, [Lisboa], n. 11, p. 133-164, 1999.

LIMA, L. Reformar a administração escolar: a recentralização por controlo remoto e a autonomia como delegação política. Revista Portuguesa de Educação, [S.1.], n. 8, v. 1, p. 57-71, 1995.

LIMA, J. Redes na educação: questões políticas e conceptuais. Revista Portuguesa de Educação [S.1.], n. 20, v. 2, p. 151-181, 2007.

LIMA, L.; AFONSO, Reformas da Educação Pública: democracia, modernização, neoliberalismo. Porto: Edições Afrontamento, 2002.

MAGALHÃES, A. A escola na transição pós-moderna. Lisboa: IIE, 1998.

MARTINS, É. Critérios de reordenamento da Rede Educativa. Lisboa: Ministério da Educação, 2000. 
MARTINS, M.; NAVE, G.; LEITE, F. As Autarquias e a Educação em 2001/2002 na Região Norte. [S.1.]: Associação Nacional de Professores, 2006.

MATTHEWS, P., et al. Política Educativa para o $1^{\circ}$ Ciclo do Ensino Básico (2005-2008): avaliação internacional. Lisboa: GEPE-ME, Lisboa, 2009.

MORIN, E. Introdução ao pensamento complexo. Lisboa: Publicações EuropaAmérica, 1991.

. O Método. Lisboa: Publicações Europa-América, 1993.

NETO-MENDES, A. A participação dos municípios portugueses na educação e a reforma do Estado - elementos para uma reflexão. In: BENNO SANDER (Org.). Por uma Escola de Qualidade para Todos. Porto Alegre: ANPAE, 2007. p. 1-22.

PERESTRELO, M. Planeamento estratégico e avaliação: metodologias de análise prospectiva. Cidades, Comunidades e Territórios, [S.1], n. 4, 2002.

PINHAL, J. Os Municípios e a provisão pública de educação. In: COSTA, J. et al. (Org.). Políticas e Gestão Local da Educação. Aveiro: Universidade de Aveiro, 2004. p. 45-60.

- Descentralização da Administração Educacional: os municípios e a autonomia das escolas. In: CONGRESSO NACIONAL DO FÓRUM PORTUGUÊS DE ADMINISTRAÇÃO EDUCACIONAL: A ESCOLA ENTRE O ESTADO E O MERCADO: O PÚBLICO E O PRIVADO NA REGULAÇÃO DA EDUCAÇÃO, 2., 2005, Lisboa, Anais..., Lisboa, 2005.

PINHAL, J. A intervenção do município na regulação local da educação. In: J. BARROSO, J. (Org.). A regulação das políticas públicas de educação: espaços, dinâmicas e actores. Educa, Lisboa, n. 4, p. 99-128, 2006.

PRATA, M. Autarquias e educação: das competências legais às competências morais - uma intervenção emergente. In: COSTA, J. A.; MENDES, A. N.; VENTURA, E A. (Org.). Políticas e gestão local da educação. Aveiro: Universidade de Aveiro, 2004. p. 173-190. 
RODRIGUES, M. L. A Escola Pública pode fazer a diferença. Coimbra: Almedina, 2010.

RUIVO, F. O Estado labiríntico: o poder relacional entre os poderes local e central em Portugal. Porto: Edições Afrontamento, 2000.

SANTOS, B. S. O Estado e as relações salariais e o bem-estar na semiperiferia. In: SANTOS, B. S. (Org.). Portugal: um retrato singular. Porto: Edições Afrontamento, 1993. p. 15-56.

. Pela mão de alice: o social e o político na pós-modernidade. Porto: Edições Afrontamento, 1994.

STOER, S. O Estado e as políticas educativas: uma proposta de mandato renovado para a escola democrática. Revista Crítica de Ciências Sociais, [S.1.], n. 41, p. 3-33, 1994.

STOER, S. Educação e mudança social em Portugal: 1970-1980, uma década de transição. Porto: Edições Afrontamento, 1986.

TEODORO, A. A construção política da educação: Estado, mudança social e políticas educativas no Portugal contemporâneo. Porto: Edições Afrontamento, 2001.

TRISTÃO, E. As Políticas Educativas Municipais: estudo extensivo nos municípios da Comunidade Urbana da Lezíria do Tejo. Dissertação (Mestrado)Ciências da Educação, Universidade de Lisboa, Lisboa, 2009. 


\section{Municipal school-charts and the reorganization of the school network in Portugal's Central Region: from demographic conditions to political decision making Abstract}

Since 2005 the municipal School-chart has established itself as a tool for the legitimization of strategic planning and for the prospective reorganization of school networks at the municipal level, its most visible effects being the closing of many hundreds of primary schools (also known as 1st cycle, i.e., first through fourth grades) and the building of hundreds of School Centers. Based on current research carried out in fourteen municipalities of Portugal's central region, the present article aims to identify and analyze major trends in the reorganization of the network of primary schools as laid out in their School-charts, with special attention being paid to how the entire process was dealt with in the context of planning. The shift from a centralizing type of planning to strategic planning allowed for the emergence of fresh rationales in the reorganization of the school network, which in turn resulted in a variety of responses on the part of the municipalities. Keywords: School-chart. Strategic planning. Municipalities. School network.

\section{Las cartas educativas municipales y la reordenación de la red escolar en el Centro de Portugal: de las condiciones demográficas a las decisiones políticas}

\section{Resumen}

Desde el año 2005 se viene observado la ascensión de la Carta Educativa como instrumento legitimador de la planificación estratégica y de la reordenación prospectiva de las redes educativas municipales, cuyos efectos más visibles se traducen en el cierre de centenas de escuelas de la enseñanza primaria $\left(1^{\circ} \mathrm{Ciclo}\right.$ de enseñanza básica) y también en la construcción de centenas de Centros Escolares. El presente artículo, basado en una investigación en marcha, realizada en catorce municipios de la región central brasileña, se focaliza en la identificación y análisis de las principales tendencias de reordenación de la red educativa del $1^{\circ}$ Ciclo preconizadas en las respectivas Cartas Educativas y cuya interpretación toma en cuenta la forma como todo el proceso se elaboró, en términos de planificación. El pasaje de una planificación de características centralizadoras a una planificación estratégica ofreció nuevas lógicas a la reordenación de la red escolar que se traducen en distintas respuestas por parte de los municipios portugueses.

Palabras-clave: Carta educativa. Planificación estratégica. Municipios. Red escolar 